\title{
FRONTIER ORBITAL SYMMETRY CONTROL OF INTERMOLECULAR ELECTRON TRANSFER
}

PROGRESS REPORT

9/15/88 - 9/15/91

by

Brian Stevens

University of South Florida

Department of Chemistry

4202 E. Fowler Avenue, FAO-126

Tampa, Florida 33620

September, 1991

prepared for the u.s. department of energ MASTER UNDER GRANT NUMBER DE-FG05-88ER13975

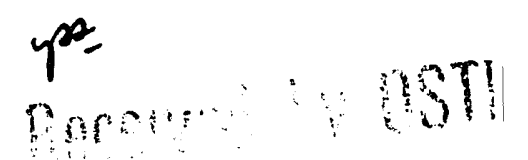




\title{
PROGRESS REPORT (9/15/88 to date)
}

\author{
Contents
}

Page

1. The Selection of Electron-Donor-Acceptor Systems $\ldots \ldots \ldots \ldots \ldots \ldots$

2. The Synthesis and Photophysical Properties of Linked Electron- ........ 1

Donor-Acceptor Systems

3. The Estimation of Photoinduced Charge-Separation Rate Constants . . . . . 6 from Fluorescence Quenching Data

4. Radical İon-Pair Recombination by Picosecond Transient $\ldots \ldots \ldots \ldots \ldots 11$ Absorption Spectroscopy

References ................................. 14

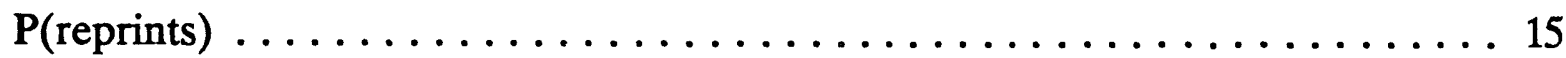

\section{DISCLAIMER}

\begin{abstract}
This report was prepared as an account of work sponsored by an agency of the United States Government. Neither the United States Government nor any agency thereof, nor any of their employees, makes any warranty, express or implied, or assumes any legal liability or responsibility for the accuracy, completeness, or usefulness of any information, apparatus, product, or process disclosed, or represents that its use would not infringe privately owned rights. Reference herein to any specific commercial product, process, or service by trade name, trademark, manufacturer, or otherwise does not necessarily constitute or imply its endorsement, recommendation, or favoring by the United States Government or any agency thereof. The views and opinions of authors expressed herein do not necessarily state or reflect those of the United States Government or any agency th:ereof.
\end{abstract}


1. The Selection of Electron-Donor-Acceptor Systems based on frontier orbital correlations $^{1}$ and predicted to exhibit rapid (adiabatic) or slow (diabatic) photoinduced charge separation followed by rapid (or slow) geminate ion recombination is a necessary prerequisite to ps transient absorption studies of radical-ion recombination dynamics in solution. The systems chosen for examination on this basis are described in section 4 (below). However a theoretical study of the role of transient intermolecular vibrational modes in modifying the overall (vibronic) symmetry of reaction surfaces involved in intermolecular electron transfer via complexes belonging to $\mathrm{C}_{\mathrm{s}}, \mathrm{C}_{2 \mathrm{v}}$ and $\mathrm{C}_{3 \mathrm{v}}$ point groups has shown ${ }^{2}$ that in each case a low frequency transient mode of the appropriate symmetry can provide an adiabatic (fast) channel for an electronically diabatic process. It is therefore concluded that both forward and reverse electron transfer via unconstrained 1:1 EDA complexes should be efficient (fast), with the corollary that donor and acceptor should be rigidly oriented (in a sink of low frequency oscillators) to minimize the energy-wasting charge recombination process, as in natural photosynthetic systems.

2. The Synthesis and Photophysical Properties of (Conjugately) Linked Electron-DonorAcceptor Systems. As anticipated the synthesis of coplanar-donor-dimer acceptor systems (DDA) was not a trivial process and emphasis was placed on the examination of more readily accessible linked EDA systems of the general structure $D(L)_{n} A$ where $(L)_{n}$ denotes an aromatic linkage typified by bianthryl $(\mathrm{n}=2)$ and $\mathrm{p}$-terphenyl $(\mathrm{n}=3)$.

Of particular interest in this connection were the properties of 1-nitro 4 "-amino, pterphenyl (NAPT), an intermediate in the synthesis of 1-cyano, 4"-amino, p-terphenyl, which 
, exhibits the structureless absorption and fluorescence bands of p-terphenyl together with an additional long-wave absorption band of equal intensity (see Table 2.1), and in certain nonpolar solvents, an additional long-wave fluorescence band which is absent in polar media (Table 2.2). This is contrary to the behaviour of TICT (twisted internal charge transfer) states believed to be responsible for the appearance of an additional long-wave fluorescence band of similar systems in polar solvents ${ }^{3}$. (It is also contrary to the behaviour of nitroaromatic compounds which are generally non-fluorescent, although the fluorescence quantum yields of NAPT are in the range of 2-4\%). The following observations must also be accommodated by a theoretical interpretation of the photophysical properties of this molecule:-
a) the relative intensities $F_{2} / F_{1}$ of the long $\left(F_{2}\right)$ and short $\left(F_{1}\right)$ wave fluorescence components increases as the excitation wavelength is increased over the double- banded absorption spectrum in dioxane, and the total emission spectrum exhibits an isoemissive point at $480 \mathrm{~nm}$.

b) both emission bands exhibit biexponential repsonse functions when excited in the short or long-wave absorption bands, but only the longer relaxation time of $F_{2}$ is independent of excitation frequency (Table 2.3);

c) the long-wave fluorescence component is selectively quenched by polar quenching species $\left(\mathrm{H}_{2} \mathrm{O}, \mathrm{CH}_{3} \mathrm{OH}, \mathrm{CH}_{3} \mathrm{CN}\right)$ at essentially a diffusion-limited rate;

d) when a solution of NAPT in methyl methracylate is polymerised by free-radical initiation, the short-wave absorption and emission $\left(F_{1}\right)$ bands are no longer evident (Table 2.2). 


\begin{tabular}{lllll} 
Fluor & \multicolumn{2}{c}{$\underline{\underline{\lambda}}_{\mathrm{a}}(\mathrm{nm})$} & \multicolumn{2}{c}{$\underline{\underline{\lambda}_{\mathrm{f}}(\mathrm{nm})}$} \\
p-terphenyl & 282 & 343 & 570 \\
1-nitro, 4' -amino-p-terphenyl & 281 & 360 & 395 & \\
1-cyano, 4'-amino-p-terphenyl & 258 & 333 & 445 & \\
1-nitro, 4'-amino-diphenyl & 255 & 378 & & 555 \\
p-nitroaniline & & 355 & - & - \\
9-nitro, 10'-aminobianthryl & 370 & 425 & 455 & 515
\end{tabular}

Table 2.2 Absorption $\left(\lambda_{2}\right)$ and emission $\left(\lambda_{f}\right)$ maxima of 1-nitro, 4'-amino-pterphenyl in various solvents

\begin{tabular}{|c|c|c|c|c|}
\hline Solvent & \multicolumn{2}{|c|}{$\underline{\lambda}_{a}(\mathrm{~nm})$} & \multicolumn{2}{|c|}{$\underline{\lambda}_{\mathrm{f}}(\mathrm{nm})$} \\
\hline p-dioxane & 281 & 360 & 395 & 570 \\
\hline diethylether & 315 & 395 & 415 & 590 \\
\hline benzene & & 360 & 387 & 535 \\
\hline methylmethracrylate & 300 & 367 & 390 & 555 \\
\hline $\mathrm{PMM}^{\mathrm{a}}$ & & 340 & & 517 \\
\hline acetonitrile & 282 & 363 & 410 & \\
\hline methanol & 279 & 361 & 417 & \\
\hline dimethylsulfoxide & 295 & 387 & 425 & \\
\hline
\end{tabular}

apolymethylmethacrylate 
The spectral identity of the short-wave absorption and emission bands of NAPT with those of unsubstituted p-terphenyl provides compelling evidence that these originate in $\pi, \pi^{*}$ transitions of the p-terphenyl linkage unperturbed by the non-bonding electrons of the substituent groups orthogonal to the $\pi$-system. It is unlikely that the long-wave absorption band is of $n \pi^{*}$ origin insofar as this is of the same intensity as the short-wave band, and it is of interest to spectulate that the long-wave absorption and emission bands originate in transitions between ground and excited states of a planar intramolecular CT(EDA) complex $-\mathrm{O}_{2} \mathrm{~N}\left(\mathrm{C}_{6} \mathrm{H}_{4}\right)_{3} \stackrel{+}{\mathrm{N}} \mathrm{H}_{2}$ in which non-bonding orbital interactions formally extend the conjugated $\pi$-electron system from 18 to 20 electrons with concomitant reduction in $\pi, \pi^{*}$ transition energy. In this context the long-wave absorption band would be the intermolecular counterpart of the well-known CT absorption bands of intermolecular EDA complexes ${ }^{4}$ and quenching of the corresponding excited state by polar molecules would be expected to involve reversible electron transfer discussed in section 3 below. If the non-polar and CT ground states are separated by a significant free-enegy barrier preventing rapid interconversion, copolymerisation or free-radical attack of the non-polar isomer could lead to its selective removal and the disappearance of short-wave absorption and fluorescence bands in polymethyl methacrylate. Alternatively the polymer environment may accommodate the CT isomer orientation exclusively. It is planned to conduct temperaturedependent studies of the absorption spectrum in various solvents during the remainder of the contract period. 
Table 2.3 Biexponential fluorescence response parameters (amplitude A, lifetime ז) for 1-nitro-4'-amino-o-terphenyl in p-dioxane

$\begin{array}{ccccccc}\underline{\lambda}_{\mathrm{ex}}(\mathrm{nm}) & \underline{\lambda}_{\mathrm{em}}(\mathrm{nm}) & \underline{\mathrm{A}}_{1} & \underline{\underline{\tau}}_{1}(\mathrm{ps}) & \underline{\mathrm{A}}_{2} & \underline{\underline{\tau}}_{2}(\mathrm{ps}) & \chi^{2} \\ 306 & 395^{\mathrm{a}} & 4.21 & 923 & 0.172 & 2900 & 1.09 \\ 306 & 570 & 4.90 & 52 & 4.74 & 601 & 1.18 \\ 350 & 395 & 1.26 & 540 & 3.51 & 1110 & 1.04 \\ 360 & 570^{\mathrm{b}} & 2.95 & 120 & 3.47 & 600 & 0.99\end{array}$

${ }^{a}$ fluorescence quantum yield $\gamma_{F}=0.0392 \pm 0.003$

${ }^{\mathrm{b}} \gamma_{\mathrm{F}}=0.0432 \pm 0.003$

Table 3.1 Recovered paran,eters for diffusion-influenced quenching of DCNA fluorescence in aconitrile

Quencher

$\underset{(\mathrm{V})}{\mathrm{E}_{\mathrm{Q}}^{+} / \mathrm{Q}} \underset{(\mathrm{pm})^{\mathrm{c}}}{\mathrm{R}} \quad \begin{aligned} & 10^{-11} \mathrm{k}^{\circ} \\ & \left(\mathrm{M}^{-1} \mathrm{~s}^{-1}\right)\end{aligned} \quad 0^{\circ} \mathrm{C} \frac{10^{9} \mathrm{D}\left(\mathrm{m}^{2} / \mathrm{s}\right)^{\mathrm{e}}}{22^{\circ} \mathrm{C} 50^{\circ} \mathrm{C}}$

benzylamine

1.2

450

$0.25^{+0.4}-0.1$

$\begin{array}{lll}3.6 & 5.0 & 6.8\end{array}$

aniline

1.02

730

$1.8^{\mathrm{d}}{ }_{5}$

$2.7 \quad 3.64 .9$

p-toluidine

0.86

790

$1.9^{\mathrm{d}}$

$2.6 \quad 3.54 .7$

$\mathrm{N}, \mathrm{N}^{\prime}$-dimethylaniline

0.81

820

$2.2^{\mathrm{d}}$

$3.1 \quad 4.05 .3$

triethylene

0.76

610

$2.2^{\mathrm{d}}$

$3.2 \quad 4.35 .4$

$\mathrm{DABCO}^{\mathrm{a}}$

0.57

760

$1.8^{\mathrm{d}}$

$2.9 \quad 3.95 .5$

TMPD $^{\mathrm{b}}$

0.16

880

$2.4^{\mathrm{d}}$

$3.2 \quad 4.25 .3$

${ }^{a}$ 1,4-diazabicyclo[2.2.2]octane

${ }^{b} \mathrm{~N}, \mathrm{~N}, \mathrm{~N}, \mathrm{~N}$-tetramethyl-p-phenylene diamine

${ }^{c} \pm 8.5 \%, \quad{ }_{ \pm \infty} 50 \% \quad e_{ \pm} 12 \%$ 
3. The Estimation of Photoinduced Charge-Separation Rate Constants from Fluorescence Quenching Data

The quenching of a fluorescence acceptor $\mathrm{F}^{*}$ by electron donor $\mathrm{Q}$ in liquids involves the sequence

$$
\mathrm{F}^{*}+\mathrm{Q} \underset{\mathrm{v}_{\mathrm{s}}}{\stackrel{\mathrm{k}_{\mathrm{D}}}{\rightleftarrows}}(\mathrm{F} . \mathrm{Q} .)^{*} \stackrel{\mathrm{vet}}{\longrightarrow} \mathrm{F}^{*}+\mathrm{Q}^{+}
$$

where the electron transfer frequency $v_{\text {et }}$ is the parameter of interest insofar as this is related to the overall free-energy change involved. However the measured quenching rate constant $\mathrm{k}_{\mathrm{Q}}$ has the photostationary form

$$
\mathrm{k}_{\mathrm{Q}}=\mathrm{k}_{\mathrm{D}} \mathrm{v}_{\mathrm{et}} /\left(\mathrm{v}_{\mathrm{s}}+\mathrm{v}_{\mathrm{et}}\right)
$$

where in the Smoluchowski-Collins-Kimball (SCK) formalism $k_{D}=4 \pi D R$ is a linear function of relative diffusion coefficient $D$ and effective electron transfer distance $R$. Limiting forms eq. 3.1 given by

$$
\begin{gathered}
\mathrm{k}_{\mathrm{Q}} \sim \mathrm{k}_{\mathrm{D}}\left(\mathrm{v}_{\mathrm{s}}<<v_{\mathrm{et}}\right) \\
\mathrm{k}_{\mathrm{Q}} \sim \mathrm{k}_{\mathrm{D}} \mathrm{v}_{\mathrm{et}} / \mathrm{v}_{\mathrm{s}}=\mathrm{k}^{\circ}\left(\mathrm{v}_{\mathrm{s}}>>\mathrm{v}_{\mathrm{et}}\right)
\end{gathered}
$$

indicate that $v_{\text {et }}$ is accessible (as $\mathrm{k}^{\circ}$ ) only in the case of inefficient quenching (eq 3.3). In the finite-sink modification ${ }^{5}$ of the SCK treatment,

$$
k_{Q}=\frac{k_{D} k^{\bullet}}{k_{D}+k^{\circ}\left(1-R / r_{o}\right)}
$$

$\mathrm{k}_{\mathrm{Q}}$ assumes a dependence on quencher concentration $\mathrm{C}$ which defines the (most porbable) nearest neighbour separation $r_{0}=(2 \pi N C)^{-1 / 4}$, and in the form

$$
\frac{1}{k_{Q}}=\frac{1}{k^{0}}+\frac{1}{4 \pi N D R}-\frac{(2 \pi N C)^{1 / s}}{4 \pi N D}
$$


provides an excellent description of $\mathrm{k}_{\mathrm{Q}}(\mathrm{C})$ with direct access to the parameter $\mathrm{D}$ and hence the effective transfer distance $R$, together with an experimental criterion of the diffusion limit ${ }^{6}$ (eq 3.2) when $1 / \mathrm{k}_{\mathrm{Q}}\left(\mathrm{R}=[2 \pi \mathrm{NC}]^{-1 / 6}\right)=1 / \mathrm{k}^{\circ}=0$. The increase in $\mathrm{R}$ with reduction in (aromatic amine) quencher oxidation potential is attributed to the increased probability of electron transfer in the solvent-separated pair which effectively masks the reduced transfer probability in the contact pair expected when the driving force $(-\Delta G)$ exceeds the reorganisation energy in the Marcus inverted region. This interpretation of the experimental data $^{7}$ (preprint attached), provides a logical explanation of the failure to observe a reduction in $\mathrm{k}_{\mathrm{Q}}$ for intermolecular quenching in liquids when electron transfer is highly exergonic ${ }^{8}$.

In the diffusion-influenced quenching region $\left(v_{s} \sim v_{e t}\right)$ the data lines $k_{Q}{ }^{-1}\left(C^{1 / s}\right)$ for the same system in media of different viscosity (and diffusion coefficient D) intersect at a quencher concentration $\mathrm{C}_{\mathrm{R}}{ }^{\text {k }}$, which in terms of equation 3.4 defines a static quenching limit at which $r_{o}=R$, diffusion is no longer a quenching prerequisite and $k_{Q}\left(C=C_{R}\right)=k^{\circ}$ (as shown in Figure 3.1). In principle these data provide access to $k^{\circ}$ in the range $\infty>k^{\circ}$ $2 k_{D}$ as illustrated by the data in Table 3.1 in which connection the following points are noted:-

a) the use of solvent temperature charge $\left(0-50^{\circ} \mathrm{C}\right)$ to modify solvent viscosity undoubtedly influences the rate constant $\mathrm{k}^{\circ}$ which is assumed to be constant in the indicated analysis;

b) propagation of the estimated uncertainty of $\pm 7 \%$ in relative quantum yield measurements leads to upper limits of $k^{\bullet}=\infty$ when $k^{\bullet}>>k_{D}$, i.e. in the region of greatest interest. The transition from reaction-limited to diffusion-limited quenching for 

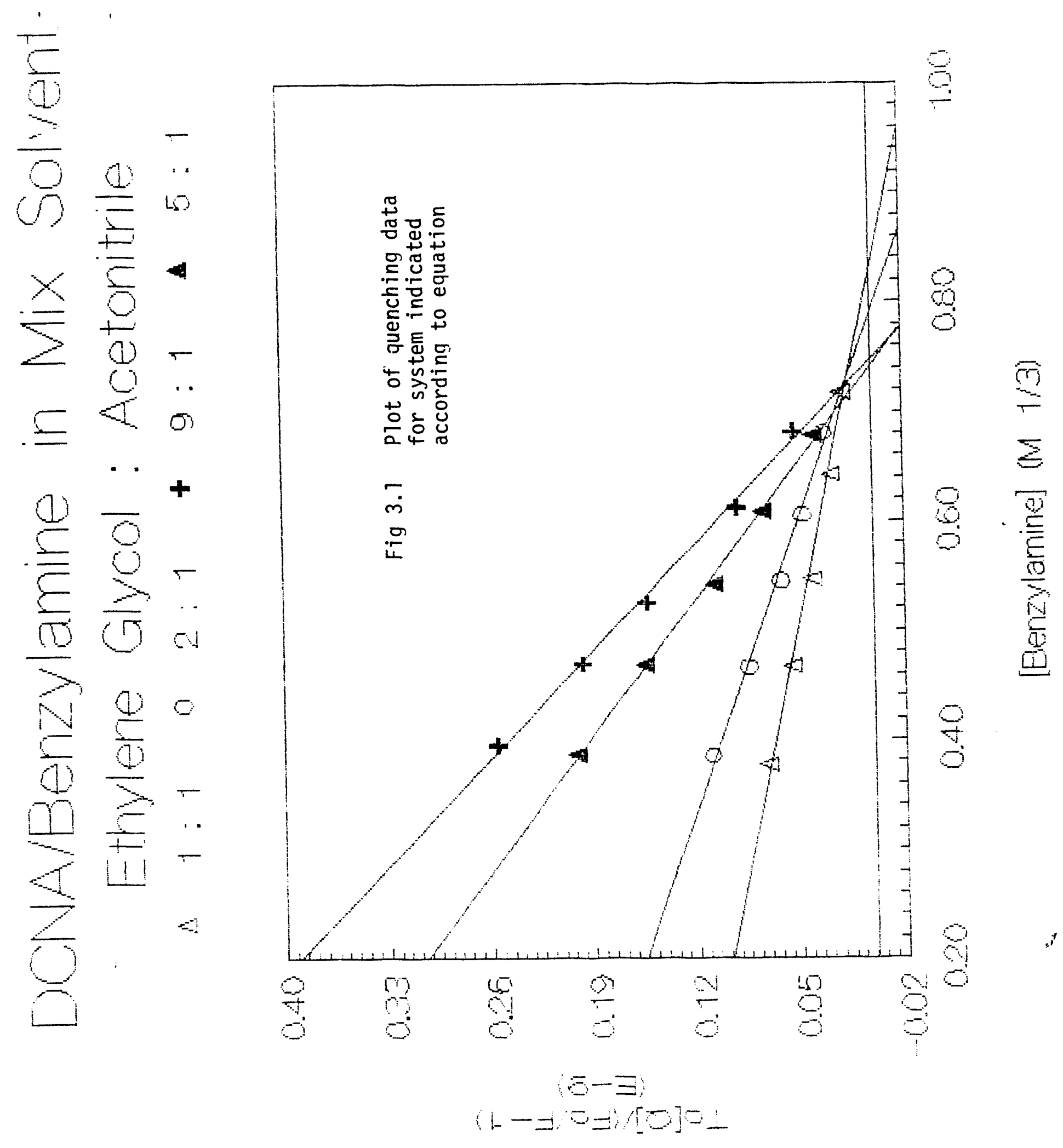
the same system by an increase in solvent viscosity is illustrated by the data given in Table 3.2.

More recently a series of mixed solvents of different viscosity and similar dielectric constants (e.g. 1,2-ethanediol and acetonitrile) have been used to vary the relative diffusion coefficient $\mathrm{D}$ at the same temperature (cf. comment a) above) These produce satisfactory data lines $\mathrm{k}_{\mathrm{Q}}^{-1}\left(\mathrm{C}^{\mathrm{k}}\right)$ with a common intersection point at $\mathrm{C}=\mathrm{C}_{\mathrm{R}}$ thereby eliminating the temperature dependence of $k^{\circ}$; however recovered estimates of $k^{\bullet}>>k_{D}$ have an upper error limit of infinity.

Integration of the time-dependent flux equation subject to the nearest quenching neighbor separation ${ }^{6}$ provides an expression for $\mathrm{k}_{\mathrm{Q}}(\mathrm{C}, \mathrm{t})$ which reduces to $\mathrm{k}^{\bullet}$ at the static quenching limit $C=C_{R}$. At this quencher concentration the fluorescence response function should therefore be exponential with relaxation time $\tau_{0}=1 / k^{\circ}$. Experimental response functions are generally found to exhibit biexponential behaviours at concentrations $C<C_{R}$, the amplitude of the shorter component $\left(\tau_{1}\right)$ increasing with $\mathrm{C}$ and approaching $100 \%$ at $C_{R}$. Table 3.3 compares values of $k^{\bullet}$ recovered from equation 3.4 in the static limit $k_{Q}\left(C_{R}\right)$ $=\mathrm{k}^{\circ}$ with these estimated from the shorter response time $\tau_{1}\left(C_{R}\right)$ where is amplitude exceeds $95 \%$. 
Table 3.2

Recovered parameters for benzylamine quenching of DCNA fluorescence in different solvents

Solvent

$\underline{\mathbf{R}^{\mathbf{c}}}$

$0^{\circ} \mathrm{C} \frac{10^{-9} \mathrm{k}^{\circ}\left(\mathrm{M}^{-1} \mathrm{~s}^{-1}\right)^{\mathrm{c}}}{22^{\circ} \mathrm{C}}$

$50^{\circ} \mathrm{C}$

$0^{\circ} \mathrm{C} \frac{10^{10} \mathrm{D}^{\mathrm{c}}\left(\mathrm{m}^{2} / \mathrm{s}\right)}{22^{\circ} \mathrm{C}} 50^{\circ} \mathrm{C}$

methanol

a

1.5

2.5

4.2

a

ethanol

a

1.7

2.3

3.7

a

1-butanol

420

$4.0^{d}$

8.3

17

28

1,2-ethanediol

420

b

0.82

1.6

3.0

anot accessible for reaction-limited quenching

${ }^{b}$ not accessible for diffusion-limited quenching

${ }^{c} \pm 8.5 \%$

average value 
- Table 3.3 Comparison of $\mathrm{k}^{\bullet}$ from static quenching limit and from fluorescence response function using DCNA as fluor

\begin{tabular}{lllll} 
Solvent & Quencher & \multicolumn{1}{l}{$10^{-10} \mathrm{k}^{\bullet}\left(\mathrm{S}_{\mathrm{R}}\right)\left(\mathrm{S}^{-1}\right)$} & \multicolumn{1}{l}{$10^{-10} / \tau\left(\mathrm{C}_{\mathrm{R}}\right)=\mathrm{k}^{\bullet}\left(\mathrm{S}^{-1}\right)(\% \tau)$} \\
$\mathrm{CH}_{3} \mathrm{OH}$ & aniline & $22.8^{+\infty}{ }_{-18.5}$ & 6.0 & 96 \\
$\mathrm{CH}_{3} \mathrm{CN}$ & benzylamine & $2.46^{+4.36}{ }_{-0.96}$ & 2.7 & 98.5 \\
$\mathrm{CH}_{3} \mathrm{OH}$ & triethylamine & $6.90^{+\infty}{ }_{-4.70}$ & $3 / 2$ & 97
\end{tabular}

Clearly the agreement is within the large limits of error quoted although the response at $C_{R}$ is not purely exponential. Other systems will be examined in this way during the remainder of the grant period. No dependence of $k^{\bullet}$ on excitation frequency was observed for the systems in Table 3.3 under either steady state or pulsed excitation, indicating that vibrational relaxation is rapid compared with the intermolecular electron transfer process.

It was found that electron transfer quenching of DCNA fluorescence by rubrene endoperoxide led to endoperoxide cycloreversion'; the low quantum yields $(\sim 7 \%)$ were almost doubled in the presence of an external magnetic field indicative of a spin rephasing requirement to form triplet $\left(\mathrm{O}_{2}\right)$ products.

\section{Radical Ion-Pair Recombination by Picosecond Transient Absorption Spectroscopy}

It is predicted on the basis of $4+4$ frontier orbital correlations that the EDA complex of naphthalene with tetracyanoethylene (TCNE) should exist in different cofacial isomeric forms belong to the $C_{2 v}$ and $C_{5}$ point groups, responsible for the appearance of 2 structureless bands (at 420 and $540 \mathrm{~nm}$ ) in the CT absorption spectrum ${ }^{1}$. On this basis it 
- was expected that the radical ion-pairs produced by selective excitation in each band should be differently oriented and undergo geminate recombination at different rates. However the time-dependent transient absorption by the naphthalene cation at $640 \mathrm{~nm}$ following selective ps excitation in each absorption band of the EDA complex with TCNE was found to exhibit no long-lived hyperbolic component characteristic of homogeneous radical-ion recombination in the solvents indicated (Table 4.1) while the fast exponential components decay with a time constant (with ps time resolution) indistinguishable from that of the excitation pulse in each absorption band. These observations indicate that charge recombination in the contact ion pair is fast (on the ps time scale) when this is produced by selective excitation in either $\mathrm{CT}$ absorption band and the efficiency of cage escape is essentially zero.

Other EDA complex systems listed in Table 4.1 were examined in the same way using the probe wavelengths indicated as $\lambda_{D}$, with similar results.

In contrast, whereas selective excitation of the TCNE/naphthalene/cyclohexane system at $355 \mathrm{~nm}$ produced no emission, excitation at $560 \mathrm{~nm}$ produced a characteristic exciplex fluorescence $\left(\lambda_{\max }=630 \mathrm{~nm}\right)$ with a biexponential response function $\left(\mathrm{A}_{1}=10.605, \tau_{1}=\right.$ $\left.52 \mathrm{ps}, \mathrm{A}_{2}=5.383, \tau_{2}=324 \mathrm{ps} ; \chi^{2}=1.474\right)$. The simplest interpretation of this behaviour involves the assignment of an exciplex $\left(\mathrm{C}_{2 v}\right)$ structure to the complex responsible for the long-wave CT absorption band. 
- Table 4.1 EDA complex absorption maxima $\left(\underline{\lambda}_{1} \underline{\lambda}_{2}\right)$ with tetracyanoethylene as acceptor

\begin{tabular}{|c|c|c|c|c|}
\hline Donor & Solvent & $\underline{\lambda}_{1}(\mathrm{~nm})$ & $\underline{\lambda}_{2}(\mathrm{~nm})$ & $\underline{\lambda}_{D}(\mathrm{~nm})$ \\
\hline naphthalene & cyclohexane & 420 & 540 & 640 \\
\hline " & $\mathrm{CH}_{2} \mathrm{Cl}_{2}$ & 429 & 550 & 640 \\
\hline$"$ & $\mathrm{CHCl}_{3}$ & 430 & 550 & 640 \\
\hline " & $\mathrm{CH}_{3} \mathrm{COOC}_{2} \mathrm{H}_{5}$ & 400 & 500 & 640 \\
\hline$"$ & $\mathrm{CH}_{3} \mathrm{CN}$ & 410 & 500 & 640 \\
\hline anisole & cyclohexane & 390 & 500 & 430 \\
\hline$n$ & $\mathrm{CH}_{2} \mathrm{Cl}_{2}$ & 384 & 507 & 430 \\
\hline " & $\mathrm{CHCl}_{3}$ & 395 & 515 & 430 \\
\hline " & $\mathrm{CH}_{3} \mathrm{COOC}_{2} \mathrm{H}_{5}$ & 320 & 470 & 430 \\
\hline " & $\mathrm{CH}_{3} \mathrm{CN}$ & 325 & 475 & 430 \\
\hline fluorene & $\mathrm{CH}_{2} \mathrm{Cl}_{2}$ & 416 & 570 & 652 \\
\hline " & $\mathrm{CHCl}_{3}$ & 430 & 570 & 652 \\
\hline " & $\mathrm{CH}_{3} \mathrm{CN}$ & 385 & 525 & 652 \\
\hline \multirow[t]{2}{*}{ phenanthrene } & $\mathrm{CH}_{2} \mathrm{Cl}_{2}$ & 370 & 530 & 415 \\
\hline & $\mathrm{CHCl}_{3}$ & 375 & 540 & 415 \\
\hline biphenyl & $\mathrm{CH}_{2} \mathrm{Cl}_{2}$ & 384 & 500 & 420 \\
\hline p-xylene & $\mathrm{CH}_{2} \mathrm{Cl}_{2}$ & 415 & 460 & 420 \\
\hline pyrene & $\mathrm{CH}_{2} \mathrm{Cl}_{2}$ & 495 & 724 & 670 \\
\hline
\end{tabular}




\section{REFERENCES}

1. B. Stevens, Chem. Phys. 122, 347 (1988).

2:. W.A. Glauser, D.J. Raber and B. Stevens, J. Phys. Chem. 95, 1976 (1991).

3. e.g. W. Rettig, J. Mol. Struct., 84,303 (1982).

4. R. Foster, "Organic Charge Transfer Complexes", Academic Press, N.Y. 1969.

5. B. Stevens, Chem. Phys. Letters, 134,519 (1987).

6. B. Stevens and D.N. McKeithan, J. Photochem. Photobiol. A40, 1 (1987); A47, 131 (1989).

7. B. Stevens, C.J. Biver III and D.N. McKeithan, Chem. Phys. Letters, submitted.

8. D. Rehm and A. Weller, Israel J. Chem., $\underline{8}, 259$ (1970).

9*. B. Stevens and T.-Y. Liu, Mol. Cryst. Liq. Cryst. 194, 133 (1991).

*Acknowledge DOE support, p(reprints) attached. 

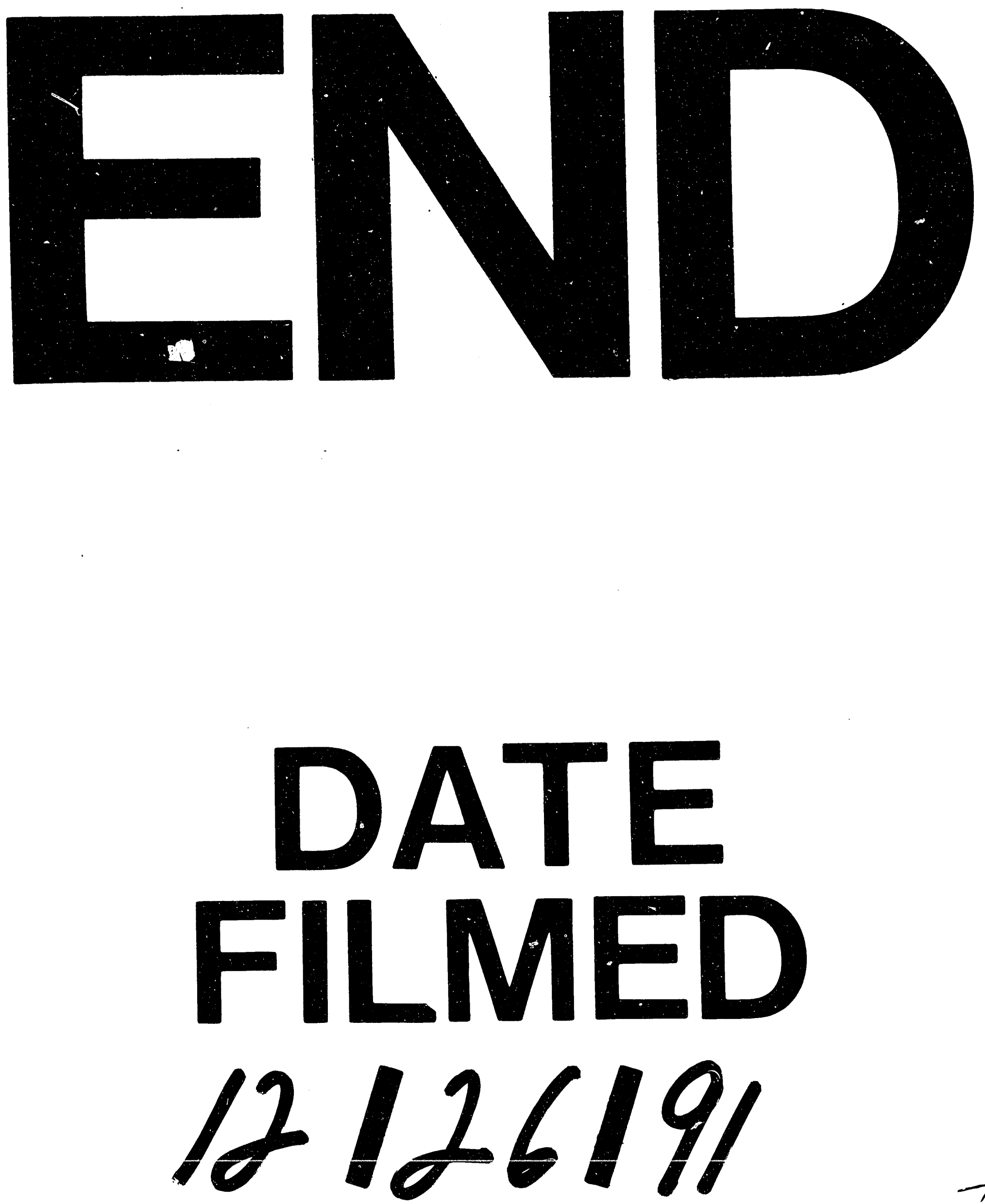
